\title{
Kernos
}

Revue internationale et pluridisciplinaire de religion grecque antique

$34 \mid 2021$

Varia

\section{Religion in Ephesos Reconsidered. Archaeology of Spaces, Structures, and Objects}

\section{Kevin Bouillot}

\section{(2) OpenEdition \\ Journals}

Édition électronique

URL : https://journals.openedition.org/kernos/3930

DOI : 10.4000/kernos.3930

ISSN : 2034-7871

\section{Éditeur}

Centre international d'étude de la religion grecque antique

\section{Édition imprimée}

Date de publication : 31 décembre 2021

Pagination : 295-297

ISBN : 978-2-87562-305-8

ISSN : 0776-3824

\section{Référence électronique}

Kevin Bouillot, "Religion in Ephesos Reconsidered. Archaeology of Spaces, Structures, and Objects », Kernos [En ligne], 34 | 2021, mis en ligne le 31 décembre 2021, consulté le 15 mars 2023. URL : http:// journals.openedition.org/kernos/3930; DOI : https://doi.org/10.4000/kernos.3930

Ce document a été généré automatiquement le 15 mars 2023.

Tous droits réservés 


\title{
Religion in Ephesos Reconsidered. Archaeology of Spaces, Structures, and Objects
}

\author{
Kevin Bouillot
}

\section{RÉFÉRENCE}

Daniel SCHOWALTER, Sabine Ladstätter, Steven J. Friesen, and Christine Thomas (dir.), Religion in Ephesos Reconsidered. Archaeology of Spaces, Structures, and Objects, Leiden/ Boston, Brill, 2020. 1 vol. $16 \times 24$ cm, xxiii + 289 p. ISBN : 978-90-04-40112-9.

1 Après un siècle et demi de fouilles archéologiques, Éphèse est sans doute l'une des cités d'Asie Mineure les mieux connues. Sa vie religieuse, particulièrement riche, est l'une des mieux documentées. Pourtant, de nombreuses zones d'ombre demeurent en la matière. Un ouvrage consacré à cette cité et à l'archéologie de sa vie religieuse est donc bienvenu. Ce volume fait suite à deux rencontres internationales organisées en 2014 par la Society of Biblical Literature, à Vienne, en collaboration avec des archéologues travaillant sur le site d'Éphèse, et appartenant notamment à l'österreichiches Archäologisches Institut. Il ambitionne de faire le point sur les recherches récentes à propos de la cité et de son histoire religieuse. Le plan ternaire de l'ouvrage conduit ses auteurs à traiter d'abord des Structures, en l'occurrence quelques-uns des principaux monuments du site (temples, grotte, habitations privées). La deuxième partie, consacrée aux Spaces, traite de certains des espaces remarquables de la cité (agora, sanctuaire d'Artémis, porte, quartiers d'habitation, etc.). Enfin la dernière partie, consacrée aux Objects, étudie, comme son nom l'indique, quelques documents iconographiques, céramiques, objets de la vie religieuse quotidienne, etc. L'objectif premier est d'exposer au lecteur, même non spécialiste, les dernières avancées de la recherche en matière d'archéologie du religieux à Éphèse. Le second est d'offrir une réflexion plus générale sur l'archéologie, ses méthodes et ses moyens modernes, et sur leurs apports à la connaissance et à l'étude des religions anciennes. En ouverture des 
articles consacrés aux Structures, Sabine Ladstätter revient d'abord sur le temple dit de Domitien, construit au $\mathrm{I}^{\mathrm{er}}$ siècle de notre ère par-dessus un quartier recouvert par son podium, détruit vraisemblablement au $\mathrm{v}^{\mathrm{e}}$ siècle et dont l'architecture a fait l'objet de nombreux débats, sur lesquels se prononce l'A. Thekla Schulz s'intéresse ensuite au temple de Sérapis, dont l'étude minutieuse, notamment par des relevés très précis et leur traitement numérique, permet de restituer quelques éléments d'architecture. Ils rendent alors possible l'identification de pratiques rituelles associées à l'eau et qui confirment par conséquent la nature égyptienne de la divinité adorée là, et donc l'attribution du temple au dieu Sérapis. Renate Pillinger se penche sur les éléments d'architecture et d'art de la grotte dite de saint Paul et sur leurs liens avec l'hagiographie apocryphe de sainte Thècle. L'histoire du site et de ses réemplois, de l'époque byzantine jusqu'au XIX ${ }^{e}$ siècle, peut ainsi être reconstituée, notamment par l'étude de graffitis. Andreas Pülz cherche des traces de la présence chrétienne, non pas seulement dans les églises de la cité, mais aussi à travers les symboles chrétiens gravés sur des bâtiments publics, dans les maisons reconstruites après les séismes de la fin du III ${ }^{\mathrm{e}}$ siècle de notre ère, dans le palais byzantin dont il confirme l'identification comme résidence épiscopale, ou encore dans l'épigraphie et ses emplois de formules bibliques.

Dirk Steuernagel ouvre la partie Spaces de l'ouvrage en revenant sur l'identification du Staatsmarkt ou "agora haute ", dans l'Est de la cité, et sur son inscription dans un prétendu programme architectural d'époque augustéenne. Les travaux qu'il a initiés en 2014 avec d'autres archéologues et historiens de l'architecture relativisent cette idée d'une construction de l'ensemble sous Auguste et concluent davantage à un chantier long et moins " politique ». Alexander Sokolicek dresse ensuite le bilan de ses propres fouilles dans le secteur de la porte magnésienne, reconstruite vers 100 avant notre ère. Outre les liens entre cette reconstruction et l'évolution du réseau routier dans la région, l'A. propose d'envisager une fonction religieuse et rituelle pour cet espace, qui aurait servi notamment aux processions, comme le laisse entendre l'épigraphie. Martin Steskal s'intéresse, lui, aux pratiques funéraires et étudie près de 1200 sites d'inhumation et de crémation (les premiers étant bien plus nombreux). Il constate le peu d'ostentation des tombeaux les plus riches et y voit la preuve d'une société éphésienne relativement égalitaire et apaisée à l'époque romaine. Hilke Thür cherche les traces laissées par Dionysos et son culte dans la cité, à travers la littérature, l'épigraphie mais aussi au théâtre ou dans quelques riches demeures éphésiennes (dont celle d'un prêtre du dieu), où de vastes salles de réception pourraient avoir accueilli des réunions privées en lien avec ce culte. Elle envisage également que le sanctuaire situé dans la cité romaine ait été initialement extérieur à la cité classique, indiquant comment les Éphésiens percevaient le dieu et son culte. Lilli Zabrana se penche sur le secteur du sanctuaire d'Artémis et sur les nombreuses structures d'époque romaine qui l'entouraient et dont les fonctions font l'objet de débats depuis leurs premières fouilles. Elle propose d'y identifier un Sébastéion, une résidence pour les prêtres du sanctuaire et/ou les bénéficiaires de l'asylie, ainsi qu'un odéon. Christine Thomas s'appuie enfin sur des études géophysiques pour tenter de retrouver les traces de la première communauté chrétienne d'Éphèse, remontant au $\mathrm{I}^{\text {er }}$ siècle de notre ère et installée dans le quartier du port. Ce dernier doit avoir accueilli des activités artisanales et commerciales, que l'auteur estime davantage compatibles avec cette nouvelle communauté religieuse. 
3 La dernière section, consacrée aux Objects, s'ouvre sur un article de François Kirbihler, qui recherche, dans les documentations épigraphique et numismatique éphésiennes, les traces des cultes rendus aux empereurs, depuis le culte initial de Roma et du Divus Iulius $\mathrm{au} \mathrm{I}^{\mathrm{er}}$ siècle avant notre ère, jusqu'au $\mathrm{III}^{\mathrm{e}}$ siècle de notre ère. Il identifie également le tournant majeur que constitue la réception, par la cité, du titre de néocore sous les Flaviens. Norbert Zimmermann cherche, dans les résidences privées de l'insula Terrace house 2, toute trace de cultes privés: sanctuaires domestiques, niches, statuettes, brûloirs à encens, graffitis, etc. Il constate ainsi la diversité des formes et des emplacements au sein de la maison, contrairement à ce qui a pu être observé à Pompéi avec les laraires. Elisabeth Rathmayr clôt cette série d'articles en s'intéressant aux statuettes et figurines en terre cuite retrouvées dans le même secteur et datant pour l'essentiel de l'époque hellénistique. Elle constate notamment le recul progressif de l'emploi de la terre cuite, au profit du marbre et d'autres matériaux plus coûteux encore, ainsi que celui des divinités grecques classiques au profit des dieux égyptiens, de Nikè et des gladiateurs, témoignant de l'enrichissement et de l'ouverture de la cité.

4 Le double objectif défini en introduction de l'ouvrage par Daniel Schowalter est manifestement atteint. L'archéologie religieuse d'Éphèse est clairement décrite dans ses grandes lignes, à travers les multiples études de cas que constituent ces articles. Et la réflexion promise quant à l'archéologie moderne, ses méthodes, leurs apports et leurs limites en matière de connaissance des religions anciennes est menée au gré des articles. L'abondance de cartes, photographies, schémas et illustrations dans chaque article, et surtout le recours systématique à la couleur, constituent une précieuse aide à la compréhension. Les bibliographies qui suivent chaque article ainsi que la bibliographie générale en fin d'ouvrage permettent d'élargir encore la perspective et d'accéder indirectement à toutes les questions que l'ouvrage ne traite pas directement. Elles compensent ainsi la principale limite de cet ouvrage : l'impossibilité de traiter en près de 270 pages d'un sujet aussi vaste et complexe que l'archéologie d'Éphèse, même sous le seul angle du religieux. Les A. ont par ailleurs fait le choix de ne pas s'en tenir aux découvertes récentes mais de consacrer plusieurs articles à la réinterprétation de données et découvertes désormais anciennes. S'ils ont ainsi renoncé à toute forme d'exhaustivité, l'ouvrage gagne en cohérence et propose une réelle et utile réflexion méthodologique voire épistémologique sur l'apport de l'archéologie à l'histoire des religions, à Éphèse et au-delà.

\section{AUTEURS}

\section{KEVIN BOUILLOT}

EPHE - PSL Paris, Université de Montréal 